able from an authentic sample (TLC, GLC, MS) which gave $[\alpha]_{\mathrm{D}}^{22}+25^{\circ}$ (c 0.89 , methanol).

Synthesis of $I V$. A solution of 6-hydroxydendroxine $(60 \mathrm{mg})$ and 1-bromo-3-methyl-2butene $(60 \mathrm{mg})$ in acetone $(2 \mathrm{ml})$ was kept at $50^{\circ}$ for $30 \mathrm{~min}$. The solvent was removed and the residue was chromatographed on alumina $(1 \times 15 \mathrm{~cm})$. Unreacted 6-hydroxydendroxine $(28 \mathrm{mg})$ was first eluted with chloroform, and $\mathrm{N}$-isopentenyl-6-hydroxydendroxinium bromide $(38 \mathrm{mg})$ was then eluted with ethanol. The bromide was filtered through a column of Dowex 1.X4 $\left(\mathrm{Cl}^{-}, 1 \times 30 \mathrm{~cm}\right)$ giving IV $(33 \mathrm{mg})$ indistinguishable from an authentio sample (optioal rotation, NMR, IR).

Acknowledgements. We are indebted to Prof. Toshihiko Okamoto (Tokyo) for samples of dendroxine and 6-hydroxydendroxine. We thank Dr. Ragnar Ryhage for measuring the mass spectra. A fellowship from Stiftelsen Bengt Lundqvists Minne to one of us (K.L.) is gratefully acknowledged. This work was supported by the Swedish Natural Science Research Council.

1. Brandänge, S., Lüning, B., Moberg, C. and Sjöstrand, E. Acta Chem. Scand. 25 (1971) 349.

2. Inubushi, Y., Ishii, H., Yasui, B., Konita, T. and Harayama, T. Chem. Pharm. Bull. (Tokyo) 12 (1964) 1175.

3. Inubushi, Y. Personal communication.

4. Elander, M. and Leander, K. Acta Chem. Scand. 25 (1971) 717.

5. Benešová, V., Herout, V. and Sorm, F. Coll. Czech. Chem. Commun. 29 (1964) 3096.

6. Okamoto, T., Natsume, M., Onaka, T., Uchimaru, F. and Shimizu, M. Chem. Pharm. Bull. (Tokyo) 14 (1966) 672.

7. Okamoto, T., Natsume, M., Onaka, T., Uchimaru, F. and Shimizu, M. Chem. Pharm. Bull. (Tokyo) 14 (1966) 676.

Received February 25, 1971.

\section{Gas-liquid Chromatography of Partially Methylated Alditols as their Acetates II}

\section{JÖRGEN LÖNNGREN and AKE PILOTTI}

Institutionen för Organisk Kemi, Stockholms Universitet, S.113 27 Stockholm, Sweden

The separation of alditol methyl ethers, 1 as their acetates, by GLC 1 has been used for some time in this laboratory, as a tool for structural studies on poly. saccharides. ${ }^{2}$ For this work, a copolymer of ethylene glycol succinate polyester and nitrile silicone polymer (ECNSS-M) has generally been used as the stationary phase. This phase affords good separations but suffers from relative low temperature stability $\left(\max .210^{\circ}\right.$ ), which gives columns of limited lifetime. Column bleeding is also a disadvantage in combined GLC-MS, resulting in increased background and contamination of the ionisation chamber.

For these reasons, various other phases have been tested, and we have now found that a silicone polymer designated OV-225, containing methyl, phenyl and cyanopropyl groups, generally gives equally good separations of methylated alditol acetates to those obtained with ECNSS-M (Table 1). OV-225 is stable up to $250^{\circ}$, which is a definite advantage. Separations of the partially methylated alditol acetates is preferably performed at $170^{\circ}$. For the most volatile acetates, a lower temperature, $155^{\circ}$, has been used in order to obtain more accurate values for the relative retention times ( $T$-values). The reproducibility of the values was examined over the temperature range $155-190^{\circ}$, and providing two internal standards with considerably different retention times were used and the retention values ( $T$-values) were estimated by interpolation, the values obtained did not differ by more than $3 \%$.

Experimental. GLC was carried out using a Perkin-Elmer 990 Gas Chromatograph. Separations were made at a glas-flow rate of $15-20 \mathrm{ml}$ nitrogen per min on a glass column $(180 \times 0.15 \mathrm{~cm})$ containing $3 \%(w / w)$ of OV-225 on Gas Chrom Q (100/120 mesh) at $170^{\circ}$ or $155^{\circ}$.

The methylated sugars were either available in this laboratory or prepared by partial methylation of suitably protected sugar deriva- 
Table 1. Retention times ( $T$-values) of methylated alditols, as their acetates, relative to 1,5-di- $O$-acetyl-2,3,4,6-tetra- $O$-methyl-Dglucitol.

\begin{tabular}{|c|c|c|}
\hline Alditol & $T^{a}$ & $T^{b}$ \\
\hline 2,3,5-Tri-O-methyl-L-arabinitol & 0.41 & 0.48 \\
\hline 2,3-Di-O-methyl-L-arabinitol & 1.07 & - \\
\hline 2,4-Di-O-methyl L-arabinitol & 1.10 & 1.40 \\
\hline 2,3,4-Tri-O-methyl-D-xylitol & 0.54 & 0.68 \\
\hline 2,3-Di-O-methyl-D-xylitol & 1.19 & 1.54 \\
\hline 2,4-Di-O-methyl-D-xylitol & 1.06 & - \\
\hline 2-Mono-O-methyl-D-xylitol & 2.15 & - \\
\hline 3-Mono-O-methyl-D-xylitol & 2.15 & 2.92 \\
\hline $2,3,4,6$-Tetra- $O$-methyl-D-glucitol & 1.00 & 1.00 \\
\hline 3,4,6-Tri-O-methyl-D-glucitol & 1.83 & 1.98 \\
\hline 2,4,6-Tri-O-methyl-D-glucitol & 1.82 & 1.95 \\
\hline 2,3,6-Tri-O-methyl-D-glucitol & 2.32 & 2.50 \\
\hline 2,3,4-Tri-O-methyl-D-glucitol & 2.22 & 2.49 \\
\hline 4,6-Di-O-methyl-D-glucitol & 3.49 & 4.02 \\
\hline 3,6-Di-O-methyl-D-glucitol & 3.73 & 4.40 \\
\hline 3,4-Di-O-methyl-D-glucitol & 4.26 & - \\
\hline 2,6-Di- $O$-methyl-D-glucitol & 3.38 & 3.83 \\
\hline 2,4-Di-O-methyl-D-glucitol & 4.21 & 5.10 \\
\hline 2,3-Di-O-methyl-D-glucitol & 4.50 & 5.39 \\
\hline 6-Mono-O-methyl-D-gluoitol & 5.0 & - \\
\hline 3-Mono-O-methyl-D-glucitol & 7.6 & 9.6 \\
\hline 2-Mono-O-methyl-D-glucitol & 6.6 & 7.9 \\
\hline 2,3,4,6-Tetra-O-methyl-D-mannitol & 0.99 & 1.00 \\
\hline 2,4,6-Tri-O-methyl-D-mannitol & 1.90 & 2.09 \\
\hline 3,4,6-Tri-O-methyl-D-mannitol & 1.82 & 1.95 \\
\hline 2,3,4-Tri-O-methyl-D-mannitol & 2.19 & 2.48 \\
\hline 4,6-Di-O-methyl-D-mannitol & 2.92 & 3.29 \\
\hline 3,6-Di-O-methyl-D-mannitol & 3.67 & - \\
\hline 3,4-Di-O-methyl-D-mannitol & 4.36 & 5.37 \\
\hline 2,4-Di-O-methyl-D-mannitol & 4.51 & 5.44 \\
\hline 2,3,4,6-Tetra- $O$-methyl-D-galactitol & 1.19 & 1.25 \\
\hline 2,3,5,6-Tetra- $O$-methyl-D-galactitol & 1.10 & 1.15 \\
\hline 2,4,6-Tri-O-methyl-D-galactitol & 2.03 & 2.28 \\
\hline 2,3,5-Tri-O-methyl-D-galactitol & 2.76 & 3.28 \\
\hline 2,3,4-Tri-O-methyl-D-galactitol & 2.89 & 3.41 \\
\hline 3,4-Di-O-methyl-D-galactitol & 5.5 & 6.93 \\
\hline 2,6-Di-O-mothyl-D-galactitol & 3.14 & 3.65 \\
\hline 2,4-Di-O-methyl-D-galactitol & 5.1 & 6.35 \\
\hline 2,3,4-Tri-O-mothyl-L-fucitol & 0.58 & 0.65 \\
\hline 2,4-Di-O-methyl-L-fucitol & 1.02 & 1.12 \\
\hline 2-Mono-O-methyl-L-fucitol & 1.43 & 1.67 \\
\hline 2,3-Di-O-methyl-L-rhamnitol & 0.92 & 0.98 \\
\hline 3-Mono-O-methyl-L-rhamnitol & 1.67 & 1.94 \\
\hline
\end{tabular}

${ }^{a} 3 \%$ OV-225 column. ${ }^{b} 3 \%$ ECNSS-M column.

tives and identified by GLC-MS. Transformation of the methylated sugars into alditol acetates was done as described earlier. ${ }^{1}$
Acknowledgement. We are indebted to Professor Bengt Lindberg for his interest. This work was supported by grants from the Swedish Natural Science Research Council, from Harald Jeanssons Stiftelse and from Emil and Wera Cornells Stiftelse.

1. Björndal, H., Lindberg, B. and Svensson, S. Acta Chem. Scand. 21 (1967) 1801.

2. Björndal, H. Hellerqvist, C.-G., Lindberg, B. and Svensson, S. Angew. Chem. 9 (1970) 610 .

Received February 22, 1971.

\section{Crystal Data on $\mathrm{I}_{\text {-Tyrosine }}$}

\section{ARVID MOSTAD, HANS MARTIN NISSEN and CHR. RøMMING Department of Chemistry, University of Oslo,
Oslo 3, Norway \\ Tnit cell dimensions and space group of $U_{\text {L-tyrosine have been reported by Khawas }}$} and Krishna Murti. ${ }^{1}$ The determination was based on X-ray powder and fibre data, as single crystals could not be obtained by ordinary methods of crystallization.

Crystals suitable for single crystal X-ray experiments may, however, be obtained by recrystallization from a solution of oxalic acid in water. A concentrated solution of oxalic acid in cold water was heated with an excess of L-tyrosine and filtered. The solution was allowed to cool down to room temperature, and after a couple of weeks needle-formed crystals with an approximately square cross section appeared. Infrared spectra showed that the crystals are identical with the original compound and that the oxalate was not formed.

Oscillation and Weissenberg photographs proved the crystals to have orthorhombic symmetry. Systematic absent reflections are $h 00$ with $h$ odd, $0 k 0$ with $k$ odd, and $00 l$ with $l$ odd; the space group is thus $P 22_{1} 2_{1} 2_{1}$.

Unit cell parameters were determined using a Picker manual diffractometer with $\mathrm{Cu} K \beta$ radiation $(\lambda=1.3922 \AA)$ and a takeoff angle of $0.5^{\circ}$. Angular measurements were made for the eight symmetry related

Acta Chem. Scand. 25 (1971) No. 3 